\title{
DESAIN STASIUN KERJA DAN POSTUR KERJA DENGAN MENGGUNAKAN ANALISIS BIOMEKANIK UNTUK MENGURANGI BEBAN STATIS DAN KELUHAN PADA OTOT
}

\author{
Ratna Purwaningsih*), Dyah Ayu P., Novie Susanto \\ Program Studi Teknik Industri, Fakultas Teknik, Universitas Diponegoro \\ Jl. Prof. Soedarto, SH, Kampus Undip Tembalang, Semarang, Indonesia 50275 \\ (Received: January 23, 2017 / Accepted: February 28, 2017)
}

\begin{abstract}
Abstrak
Pekerjaan manual masih banyak ditemui pada berbagai aktivitas kerja. Pekerjaan manual yang dikerjakan secara berulang (repetitive) dengan gerakan kerja monoton dan waktu kerja yang lama berpotensi menimbulkan kelelahan kerja. Pada gerak monoton repetitive terjadi pembebanan otot yang terus menerus. Postur kerja yang salah membuat kelelahan menjadi lebih cepat terjadi. Postur kerja yang tidak baik ini seringkali diakibatkan oleh desain fasilitas kerja yang kurang memperhatikan kesesuaian dengan penggunanya. Pada pekerja laundry aktivitas menyetrika pakaian merupakan kerja repetitive monoton yang kurang didukung fasilitas yang sesuai. Postur kerja dengan berdiri dan terjadi twist serta seringkali membungkuk. Operator setrika harus melakukan kegiatan setrika selama lebih dari 8 jam. Penelitian bertujuan melakukan redesain pada stasiun kerja setrika agar diperoleh postur kerja yang baik. Perancangan stasiun kerja menggunakan software Jack 8.2. Stasiun kerja yang terdiri dari meja dan kursi dirancang dengan memperhatikan antropometri dan kebutuhan gerak operator. Evaluasi desain dilakukan dengan mengevaluasi postur kerja dengan menggunakan analisis biomekanik, menggunakan analisis toolkit yang meliputi analisisi SSP, LBA, RULA, dan OWAS. Dari hasil evaluasi, dihasilkan postur usulan yang diberikan adalah, pekerja duduk pada kursi dengan posisi tubuh tegap, arah kepala sejajar dengan arah objek yang dikenai pekerjaan, dan pekerja dihindarkan dari posisi kerja membungkuk dan twist.
\end{abstract}

Kata Kunci : desain stasiun kerja; postur kerja; kelelahan otot; biomekanik

\begin{abstract}
( The Design of Working Station and Working Posture Using Biomechanic Analysis to Reduce Static Load and Musculoskeletal Disorder).

The work that is done manually is usually done repeatedly with monotonous movements and long working hours. If the muscle's working too hard, the muscle will be found damage and fatigue. The right working posture can improve the worker's ability to finish the job. Wrong posture is often caused by the facility design that unsuitable to operator. In the laundry workers ironing clothes activity is monotonous and repetitive work which is lacking in appropriate facilities. Work posture by standing up, often bent and twist. Ironing operator do their activities for more than 8 hours. The research aims to redesign the work station in order to obtain a good working posture. The design of work stations using Jack software 8.2. Work station consisting of a table and chairs designed with anthropometric and consider the motion of operator. Work station design used Jack Software 8.2. Evaluation of work posture used biomechanic analysis covering analysis of SSP, LBA, RULA, and OWAS. The result of evaluation is a posture suggested that the worker should sit on a chair with a sturdy body, the head is parallel toward to the direction of the object, and workers are prevented from bending and twist position.
\end{abstract}

\footnotetext{
${ }^{*}$ Penulis Korespondensi.

email:_ratna.tiundip@gmail.com
} 
Keywords : muscle fatigue; working posture; work station; biomechanic

\section{Pendahuluan}

Pekerjaan secara manual masih banyak ditemui dalam berbagai aktivitas kerja. Pekerjaan manual yang dilakukan secara berulang atau repetitif dengan gerakan kerja yang monoton dan waktu kerja yang lama berpotensi menimbulkan kelelahan kerja. Otot merupakan organ vital yang bertugas menghasilkan gerakan pada tubuh. Semua gerakan dalam tubuh, baik gerakan sadar maupun tak sadar dikendalikan oleh otot. Otot dalam tubuh akan menghasilkan panas yang berguna untuk menjaga tubuh tetap hangat dan menjaga aliran darah tetap berjalan dengan lancar. Otot memiliki kemampuan untuk kontraksi, relaksasi, mengembang dan menyempit sehingga memungkinkan terjadinya banyak gerakan tubuh (Hall, 2003). Otot yang bekerja terlalu berat akan mengalami kerusakan atau mengalami kelelahan. Kegiatan yang monoton dengan waktu yang cukup lama dapat pula menyebabkan keluhan pada sistem muskuloskeletal. Keluhan muskuloskeletal adalah keluhan pada bagian otot rangka yang dirasakan oleh seseorang mulai dari keluhan ringan sampai sangat sakit. Apabila otot menerima baban statis secara berulang dan dalam waktu yang lama, maka akan menyebabkan keluhan yang berupa kerusakan sendi, ligamen dan tendon. Keluhan tersebut sering disebut musculoskeletal disorders atau MSDs (Grandjean, 2000).

Kelelahan atau kerusakan pada otot dapat mengakibatkan spasm (kram otot), kejang otot, kehilangan keseimbangan, dan terkilir. Kelelahan otot dapat pula menyebabkan nyeri yang parah hingga menyebabkan loss sensation (mati rasa) pada bagian tubuh yang terbebani (Ng, Swapna, Michelle, \& Acharya, 2011). Kelelahan otot ini juga bias diakibatkan karena postur kerja yang kurang benar.

Terdapat 3 macam postur kerja atau posisi tubuh saat bekerja yaitu posisi duduk, berdiri, dan duduk berdiri. Sikap kerja kombinasi atau sikap kerja duduk berdiri merupakan sikap kerja paling sesuai terhadap semua jenis pekerjaan yang terdiri dari beberapa sub bagian tugas dan pekerjaan yang sering melakukan gerak dalam lingkungan kerja (Helander, 2006)

Salah satu postur kerja berdiri maupun duduk yang cukup lama adalah pada aktivitas menyetrika pakaian. Dalam praktek kerjanya, operator atau pekerja laundry di bagian ironing (setrika baju) harus melakukan kegiatan setrika selama lebih dari 8 jam, dengan posisi berdiri, kerja repetitive $\mathrm{dn}$ monoton. Dalam menyelesaikan pekerjaan ini, operator harus mengambil baju dimana baju biasanya diletakkan di samping bawah tempat kerja sehingga operator harus membungkuk dan melakukan gerakan twist. Pada sebagian besar pekerja laundry yang melakukan kegiatan setrika dengan posisi duduk, kursi yang digunakan adalah kursi plastik tanpa sandaran sehingga menyebabkan punggung pekerja sakit. Meja kerja yang terlalu tinggi juga menjadi salah satu alasan pekerja tidak merasa nyaman melakukan pekerjaannya.

Dari hasil evaluasi di atas, perlu dilakukan analisis pada desain stasiun kerja setrika yang baik. Setelah itu perlu dilakukan evaluasi mengenai postur kerja sebagai akibat desain hasil rancangan. PErancangan dilakukan dengan bantuan software Jack. Software Jack mensimulasikan bagaimana model manusia pada lingkungan virtual dan dapat berinteraksi dengan objek dan lingkungan kerja serta mendapatkan respon balik yang tepat dari objek dan lingkungan tersebut. Dengan menggunakan software Jack, akan dilakukan analisis biomekanik yaitu low back analysis, static strength prediction, rapid upper limb assessment, dan OWAS. Analisis tersebut akan digunakan untuk menentukan postur tubuh terbaik pekerja sehingga keluhan dan beban statis pada otot dapat berkurang.

\section{Tinjauan Pustaka}

Desain fasilitas kerja yang baik harus berorientasi pada manusia sebagai pengguna peralatan tersebut. Desain fasilitas harus mempertimbangkan dimensi tubuh pengguna atau anthropometri pengguna. Antropometri merupakan cabang dalam human sciences yang membahas mengenai ukuran tubuh, bentuk, kekuatan, dan kapasitas kerja. Antropometri merupakan cabang penting dalam ilmu ergonomi (Pheasant, 2003). Antropometri berasal dari kata "anthro" yang memiliki arti manusia dan "metri" yang memiliki arti ukuran. Menurut Wignjosoebroto (2000), antropometri adalah studi yang berkaitan dengan pengukuran dimensi tubuh manusia.

Ketinggian meja kerja yang terlalu rendah sering menjadi penyebab postur kerja yang membungkuk. Perancangan fasilitas sesuai anthropometri pekerja dapat membantu mendapatkan postur kerja yang nyaman bagi pekerja, baik itu postur berdiri, duduk atau postur kerja lainnya. Pada beberapa pekerjaan, terdapat postur kerja yang tidak alami dan berlangsung dalam jangka waktu yang lama. Hal ini dapat mengakibatkan keluhan sakit pada tubuh. Beberapa hal yang perlu diperhatikan yang berkaitan dengan postur tubuh, antara lain yaitu semaksimal mungkin mengurangi keharusan operator untuk bekerja dengan postur membungkuk dengan frekuensi yang sering dan jangka waktu lama. Selain itu, seorang pekerja juga seharusnya tidak menggunakan jangkauan maksimum (Susihono dan Prasetyo,2012).

Kerja monoton seringkali menyebabkan pembebanan yang monoton pada berbagai bagian otot dan mengakibatkan kelelahan. Kelelahan adalah suatu bentuk mekanisme perlindungan tubuh agar tubuh 
terhindar dari kerusakan lebih lanjut sehingga terjadi pemulihan setelah istirahat. (Grandjean, 2000) menerangkan kelelahan biasanya menunjukan kondisi yang berbeda untuk setiap individu, namun semua jenis kelelahan bermuara pada hilangya efisiensi dan penurunan kapasitas kerja serta ketahanan tubuh. Salah satu jenis kelelahan, adalah kelelahan otot. Kelelahan otot adalah tremor pada otot atau perasaan nyeri pada otot (Husein, Kholil, \& Sarsono, 2009).

Keluhan muskuloskeletal adalah keluhan pada bagian otot rangka yang dirasakan oleh seseorang mulai dari keluhan ringan sampai sangat sakit. Apabila otot menerima baban statis secara berulang dan dalam waktu yang lama, maka akan menyebabkan keluhan yang berupa kerusakan sendi, ligamen dan tendon. Keluhan tersebut sering disebut musculoskeletal disorders (MSDs) (Grandjean, 2000).

Postur kerja, selain dapat dievaluasi dengan mengukur beban pada otot, juga dapat dievaluasi dengan biomekanika kerja. Biomekanika adalah disiplin ilmu yang mengintregasikan faktor-faktor yang mempengaruhi gerakan manusia yang diambil dari pengetahuan dasar seperti fisika, matematika, kimia, fisiologi, anatomi, dan konsep rekayasa untuk menganalisa gaya yang terjadi pada tubuh. Dari pengertian tersebut biomekanika mencoba memberikan gambaran guna meminimumkan gaya dan momen yang dibebankan pada pekerja, dengan tujuan agar tidak terjadi kecelakaan kerja. (Madyana, 1996).

Pada penelitian ini perancangan stasiun kerja akan dilakukan dengan software Jack. Kondisi tubuh dari manekin dalam software ini dapat disesuaikan sesuai dengan kondisi asli dari tubuh antropometri manusia aktual. Keunggulan dari software Jack adalah dalam hal menciptakan simulasi manusia dengan karakteristik ergonomi, biomekanik, dan antropometri yang kemudian dapat dioperasikan dan bertindak layaknya di dunia nyata.

Dalam penelitian ini, secara biomekanika terdapat beberapa analisis dalam analisis toolkit jack yang digunakan, yaitu :

1. Low Back Analysis (LBA)

Digunakan untuk mengevaluasi gaya yang diterima oleh tulang belakang pada postur dan kondisi tertentu. Dalam analisis LBA, terdapat dua hal yang menjadi fokus utama yaitu pada muscle tension yang menjelaskan mengenai gaya yang terjadi pada beberapa otot yaitu erecctor spine, latissimus dorsi, erternal oblique, internal oblique, dan rectus abdominus dan menggambarkan momen gaya yang terjadi pada L4 dan L5.

2. Static Strength Perediction (SSP)

Digunakan untuk mengevaluasi presentase dari suatu populasi pekerja yang memiliki kekuatan untuk melakukan pekerjaan yang diberikan pada virtual human berdasarkan postur tubuh, jumlah energi yang dibutuhkan, dan antropometri.

3. Ovako Working Posture Analysis System (OWAS)

Digunakan untuk memperkirakan kecukupan waktu pemulihan yang tersedia untuk suatu pekerkajan sehingga dapat menghindari kecelakaan kerja.

4. Rapid Upper Limb Assessment (RULA)

Merupakan metode ergonomi yang digunakan untuk mengevaluasi postur kerja seorang pekerja terhadap faktor resiko dalam melakukan pekerjaannya.

\section{Hasil dan Pembahasan}

Pengolahan data dilakukan dengan membandingkan data hasil penilaian dari software terhadap postur kerja berdiri dan postur kerja duduk dengan desain stasiun kerja hasil rancangan. Postur kerja yang memberikan nilai yang lebih baik akan menjadi postur kerja yang direkomendasikan. Postur kerja yang dipilih adalah postur kerja saat mengambil pakaian, postur kerja saat menyetrika pakaian, dan postur kerja saat meletakkan pakaian yang telah disetrika pada tempat yang disediakan.

Postur kerja ini akan dilakukan dengan dua kondisi stasiun kerja, yaitu yang pertama kondisi kerja yang menempatkan operator pada posisi berdiri saat bekerja (gambar 2) dan kondisi stasiun kerja yang menempatkan operator pada posisi duduk saat bekerja (gambar 3). Setelah itu, masing-masing kondisi akan dianalisis menggunakan analisis (Static Strength Prediction) SSP, (Low Back Analysis) LBA, (Ovako Working Posture Analysis) OWAS, dan (Rapid Upper Limb Assessment) RULA dengan bantuan software Jack 8.2. Hasil analisis postur kerja awal ditunjukan pada tabel 1 .

SSP digunakan untuk mengetahui seberapa besar prosentase suatu postur kerja dapat diterima oleh suatu populasi tertentu. Sehingga dengan SSP akan diketahui apakah postur kerja yang dilakukan dapat diterima atau tidak. Analisis LBA akan menunjukan tekanan, momen, dan gaya yang diterima pada otot-otot tulang belakang (Erector Spine, Latimus Dorsi, External Oblique, Interal Oblique, Rectus Abdominus) sehingga dapat diketahui beban yang diterima otot saat melakukan pekerjaan. Analisi RULA digunakan untuk mengetahui apakah postur kerja yang dilakukan pekerja aman dilakukan atau tidak. Sedangkan analisis OWAS dilakukan untuk mengetahui tingkat urgensi suatu postur tubuh. Tabel 1 menunjukan hasil analisis postur kerja yang dilakukan operator pada masing-masing posisi kerja yaitu duduk atau berdiri. 
Hasil analisis SSP, LBA, RULA, dan OWAS selanjutnya akan digunakan untuk merancang stasiun kerja baru dan postur kerja baru (gambar 5) sebagai usulan permasalahan yang ada.
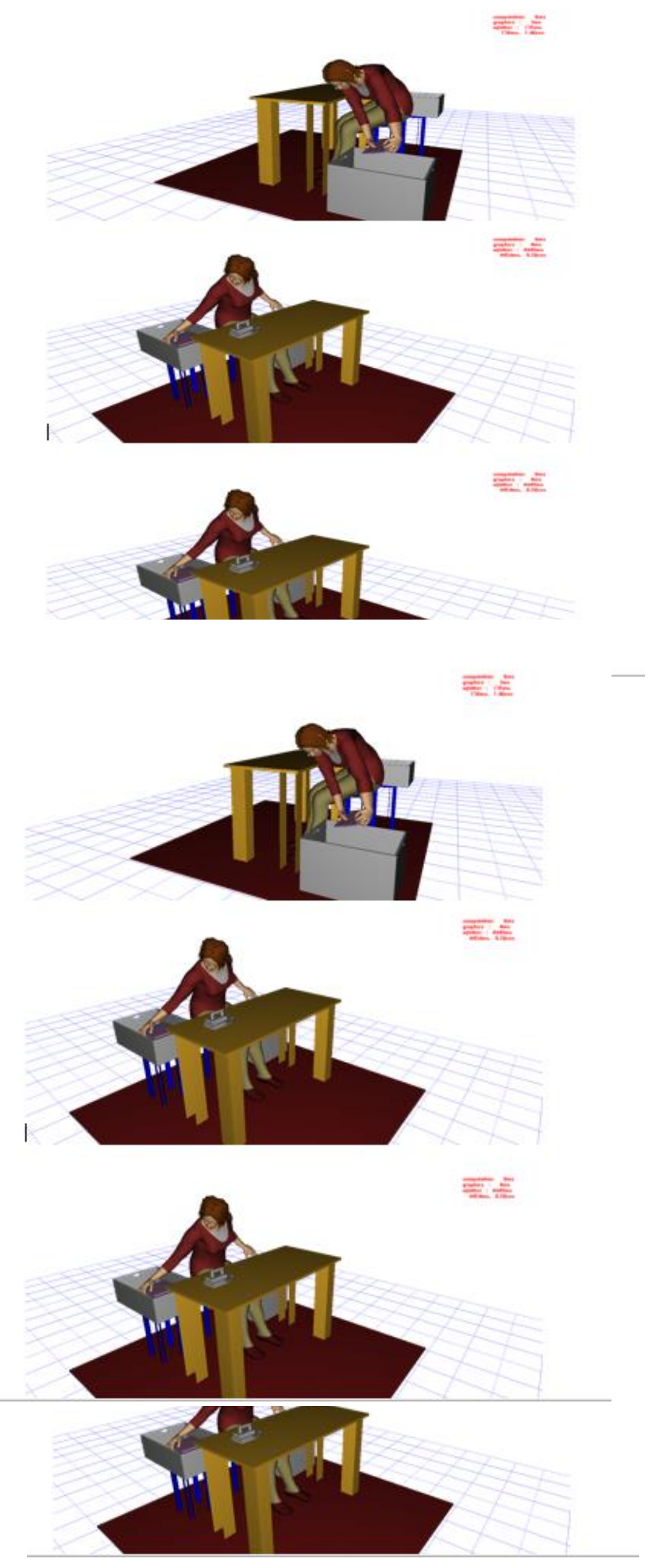

Gambar 2. Posisi Kerja Setrika dengan Duduk 
Hasil analisis SSP, LBA, RULA, dan OWAS selanjutnya akan digunakan untuk me rancang stasiun kerja baru dan postur kerja baru (gambar 5) sebagai usulan permasalahn yang ada. Staiun kerja yang baru dirancangan berdasarkan antropometri tubuh wanita Indonesia sehingga stasiun kerja usulan dapat digunakan untuk semua pekerja setrika. Berikut pada tabel 2 merupakan dimensi yang digunakan dalam perancangan stasiun kerja baru.

Tabel 1. Rekapitulasi Analisis Postur Kerja Awal

\begin{tabular}{ccccc}
\hline Postur & Kondisi & OWAS & $\begin{array}{c}\text { LBA } \\
\text { (N) }\end{array}$ & RULA \\
\hline $\begin{array}{c}\text { Mengambil } \\
\text { pakaian }\end{array}$ & $\begin{array}{c}\text { Aktual } \\
\text { berdiri }\end{array}$ & 2 & 1118 & 7 \\
& $\begin{array}{c}\text { Aktual } \\
\text { duduk }\end{array}$ & 2 & 971 & 5 \\
\hline Menyetrika & $\begin{array}{c}\text { Aktual } \\
\text { berdiri }\end{array}$ & 2 & 901 & 5 \\
pakaian & $\begin{array}{c}\text { Aktual } \\
\text { duduk }\end{array}$ & 2 & 765 & 5 \\
\hline $\begin{array}{c}\text { Meletakkan } \\
\text { pakaian }\end{array}$ & $\begin{array}{c}\text { Aktual } \\
\text { berdiri } \\
\text { Aktual } \\
\text { duduk }\end{array}$ & 2 & 831 & 4 \\
\hline
\end{tabular}

Setelah rancangan satiun kerja baru jadi (ditunjukan pada gambar 4) maka akan dilakukan analisi biomekanik kembali menggunakan analisis SSP, LBA, RULA dan OWAS dengan bantuan software Jack 8.2. Hasil analisis postur kerja dengan stasiun kerja baru ditunjukan pada tabel 3
Tabel 2. Dimensi Stasiun Kerja Baru

\begin{tabular}{ccccc}
\hline Part & Dimensi & $\begin{array}{c}\text { Persent } \\
\text { il }\end{array}$ & $\begin{array}{c}* \text { Ukuran } \\
(\mathbf{c m})\end{array}$ & $\begin{array}{c}* \text { Total } \\
(\mathbf{c m})\end{array}$ \\
\hline $\begin{array}{c}\text { Sandar } \\
\text { an } \\
\text { kursi }\end{array}$ & $\begin{array}{c}\text { Lebar } \\
\text { bahu } \\
\text { bagian } \\
\text { atas }\end{array}$ & $95 \%$ & 38 & 38 \\
$\begin{array}{c}\text { Kedala } \\
\text { man } \\
\text { kursi }\end{array}$ & $\begin{array}{c}\text { Panjang } \\
\text { popliteal }\end{array}$ & $5 \%$ & $\begin{array}{c}38+3.8 \\
(\text { allowan } \\
\text { ce } 10 \%)\end{array}$ & 42 \\
$\begin{array}{c}\text { Lebar } \\
\text { kursi }\end{array}$ & $\begin{array}{c}\text { Lebar } \\
\text { pinggul }\end{array}$ & $95 \%$ & $\begin{array}{c}38+3.8 \\
(\text { allowan } \\
\text { ce 10\%) }\end{array}$ & 42 \\
Tinggi & $\begin{array}{c}\text { Tinggi } \\
\text { popliteal } \\
\text { duduk }\end{array}$ & $5 \%$ & 42 & 42 \\
\hline
\end{tabular}

Tabel 3. Rekapitulasi Hasil Pengolahan Data Setelah Perbaikan

\begin{tabular}{cccc}
\hline Postur & OWAS & $\begin{array}{c}\text { LBA } \\
\text { (Newton) }\end{array}$ & RULA \\
\hline $\begin{array}{c}\text { Mengambil } \\
\text { pakaian }\end{array}$ & 1 & 350 & 3 \\
$\begin{array}{c}\text { Menyeterika } \\
\text { pakaian }\end{array}$ & 1 & 446 & 3 \\
$\begin{array}{c}\text { Meletakkan } \\
\text { pakaian }\end{array}$ & 1 & 551 & 3 \\
\hline
\end{tabular}




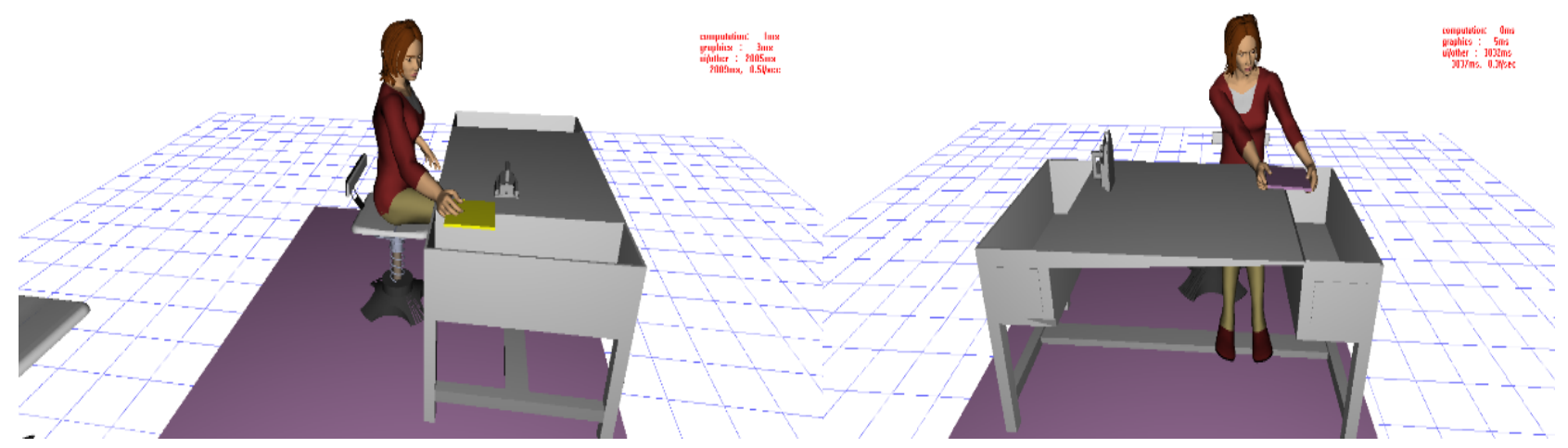

Gambar 3. Postur Kerja Usulan

sempritalion: $11 \mathrm{nn}$

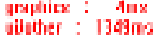
13hame, II./thent
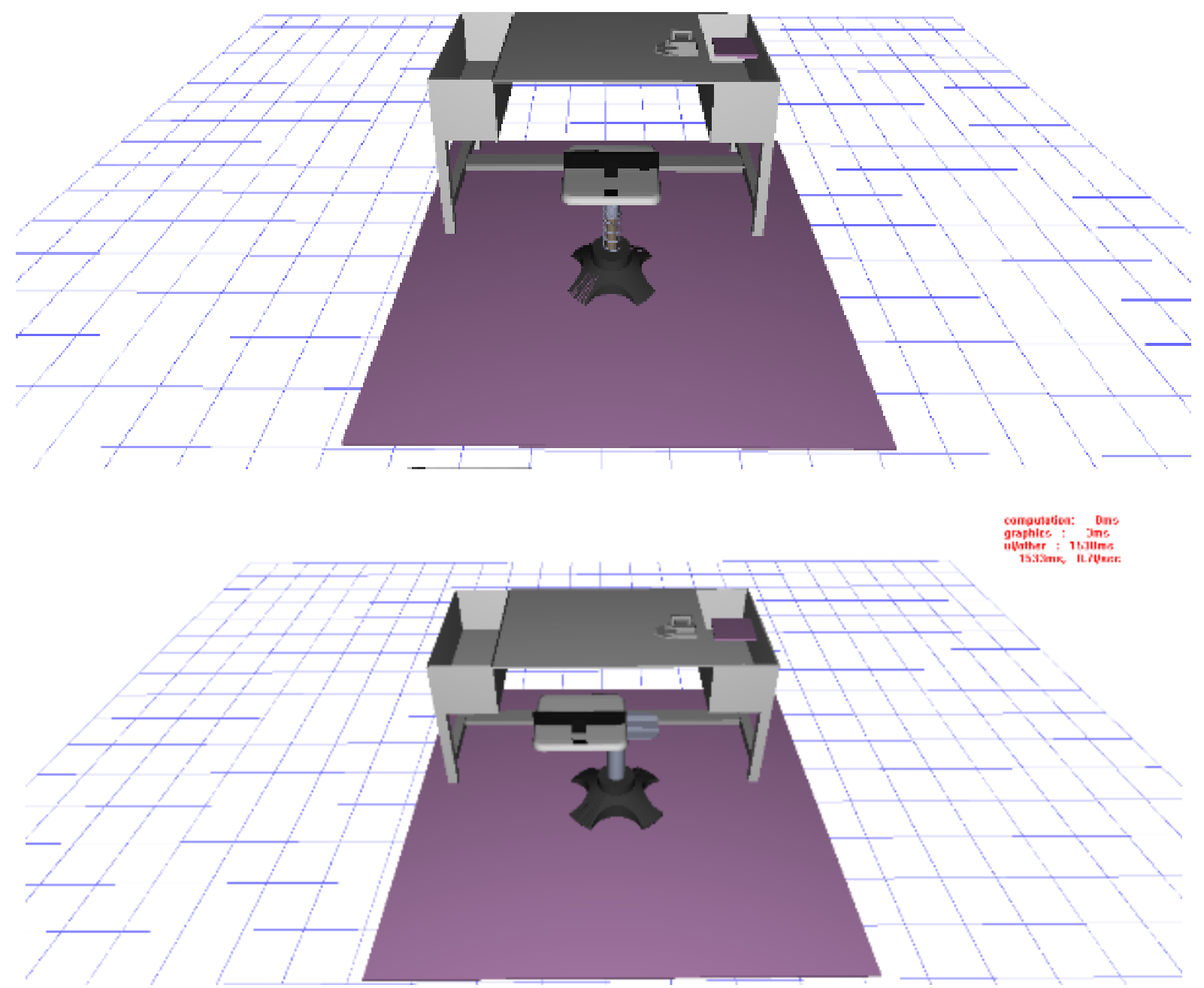

Gambar 4. Stasiun Kerja Usulan, Kursi Kerja dapat Bergeser 


\section{Evaluasi Stasiun Kerja Hasil Redesain}

Evaluasi dilakukan untuk mengetahui apakah redesain yang dilakukan memberikan postur kerja lebih bagus dari paostur kerja sebelumnya. Staisun kerja hasil redesain dibuat lebih hemat dalam luas area kerja yang dibutuhkan. Adanya peniadaan keranjang pakaian dan digantinya rak pakaian yang sudah terdapat pada meja. Sandaran kaki menjadi poin yang mencolok yang membedakan stasiun kerja aktual dengan usulan. Sandaran kaki sangat diperlukan, terlebih untuk pekerjaan yang dikerjakan dalam waktu yang lama. Kursi kerja dirancang menggunakan data antropometri sehingga pekerja yang duduk merasa lebih nyaman. Selain itu, konsep kombinasi gerakan duduk dan berdiri diterapkan pada pembuatan kursi kerja ini. Dengan gaya pegas yang menyesuaikan gerakan operator, pekerja dapat bergerak ke atas (setengah berdiri atau berdidi) sesuai dengan kebutuhan pekerja.

Untuk kegiatan mengambil pakaian, nilai OWAS yang dihasilkan pada kondisi aktual untuk posisi duduk maupun berdiri adalah 2. Setelah dilakukan perbaikan, nilai OWAS berubah menjadi 1 . Hal ini menunjukan bahwa postur usulan lebih baik dibandingkan aktual. Hal yang sama juga terjadi pada postur saat menyetrika pakaian. Nilai OWAS yang semula adalah 2 berubah menjadi 1 setelah dilakukannya perbaikan. Perubahan ektrim terdapat pada potur meletakkan pakaian. Pada kondisi aktual nilai OWAS untuk posisi kerja berdiri adalah 2 sedangkan untuk posisi kerja duduk adalah 4 . Setelah dilakukan perubahan postur menggunakan postur usulan, nilai OWAS berubah menjadi 1 .

Untuk nilai LBA, semakin kecil gaya yang dikeluarkan oleh tulang belakang saat melakukan kerja, maka semakin baik dan aman peerjaan yang dilakukan. Untuk postur mengambil pakaian dengan posisi kerja berdiri nilai LBA yang ditampilkan adalah $1118 \mathrm{~N}$ dan untuk posisi duduk adalah 971 N. Nilai LBA ini cenderung masih besar dikarenakan postur tubuh seberti membungkuk masih dilakukan. Setelah mengalami perubahan, nilai LBA yang ditunjukan adalah sebesar $350 \mathrm{~N}$. Untuk postur kerja menyetrika dengan posisi kerja berdiri, nilai LBA yang ditunjukan adalah $901 \mathrm{~N}$ dan untuk posisi duduk adalah sebesar 765 N. Setelah dilakukan perbaikan nilai LBA dapat diturunkan menjadi $446 \mathrm{~N}$. Untuk postur ketiga yaitu meletakkan pakaian, untuk posisi kerja berdiri nilai LBA yang ditunjukan adalah $831 \mathrm{~N}$ dan untuk posisi duduk adalah 1349 N. Setelah dilakukan perbaikan, nilai LBA untuk posisi meletakkan pakaian menjadi $551 \mathrm{~N}$.

Pada postur kerja mengambil pakaian, nilai RULA yang dihasilkan pada posisi duduk adalah 5 dan pada posisi berdiri adalah 7 . Nilai ini sangat mengkhawatirkan, karena kemungkinan terjadinya cidera sangat tinggi. Dari postur kerja usulan, didapatkan nilai RULA sebesar 3. Untuk postur kerja menyetrika pakaian, nilai RULA yang dihasilkan pada posisi duduk dan pada posisi berdiri adalah 5. Setelah dilakukan perbaikan nilai RULA berhasil diturunkan menjadi 3. Untuk postur kerja meletakkan pakaian, nilai RULA yang dihasilkan pada posisi duduk adalah 6 dan pada posisi berdiri adalah 4 . Setelah dilakukan perbaikan nilai RULA berhasil diturunkan menjadi 3.

\section{Kesimpulan}

Rekomendasi yang diberikan adalah dengan menggunakan rancanagan stasiun kerja baru, dimana staisun kerja tersebut terdiri dari meja dan kursi yang telah didesain sesuai dengan antropometri tubuh pekerja dan sesuai dengan gerak tubuh kerja yang dibutuhkan pekerja sehiggga terhindar dari postur kerja yang berbahaya. Postur usulan yang diberikan adalah, pekerja duduk pada kursi (stasiun kerja usulan) dengan posisi tubuh tegap, arah kepala sejajar dengan arah objek yang dikenai pekerjaan, dan pekerja dihindarkan dari posisi kerja membungkuk dan posisi kerja twist. Dengan menerapkan stasiun kerja baru dan postur kerja baru terbukti dengan analisis biomekanik dapat menurunkan beban statis pada otot sehingga dapat disimpulkan bahwa keluhan pada otot muskuloskeletal dapat berkurang.

\section{Daftar Pustaka}

Company, E. K. (2003). Kodak's Ergonomic Design for People at Work. USA: Kodak Company.

Grandjean, E. (2000). Fitting The Task to The Man. A Textbook of Occupational of Ergonomic. London: Taylor \& Francis.

Hall, S. (2003). Basic Biomechanics. United Kingdom: McGraw Hill.

Helander, M. (2006). A Guide to Human Factors and Ergonomics. United Kingdom: Taylor \& Francis Grup.

Husein, T., Kholil, M., \& Sarsono, A. (2009). Perancangan Sistem Kerja Ergonomis Untuk Mengurangi Tingkat Kelelahan. INASEA, Vol 10 No. 1, 45-58.

Madyana, A. (1996). Analisis Perancangan Kerja dan Ergonomi. Yogyakarta: Universitas Atma Jaya Yogyakarta.

Middlesworth, M. (1993). A Step by Step Guide RULA. Ergonomic Plus, 1-13.

Ng, E., Swapna, G., Michelle, Y. L., \& Acharya, U. R. (2011). Classification of Normal, Neuropathic, and Myopathic Electromyograph Signal Using Non Linear Dynamic Method. Journal of Medical Imaging and Health Informatic, 375380. 
Nurmianto, E. (2003). Ergomoni Konsep Dasar dan Aplikasinya. Surabaya: Guna Widya.

Pheasant, S. (2003). Bodyspace (Anthropometry, Ergonomics and The Design of Work. London: The Estate of Stephen Phesant.

Santoso, B. (2004). Pengaruh Posisi Kerja Terhadap Timbulnya Nyeri Punggung Bawah Pada Pengrajin Rotan di Desa Transan Kabupaten Sukoharjo. Info Kesehatan, 54-68.

Sukania, I. W., Widodo, L., \& Gunawan, D. (2012). Perancangan Ulang Stasiun Kerja Untuk Mengurangi Keluhan Biomekanik Pada Aktivitas Loundry di PT X. Seminar Nasional Mesin dan Industri, 366-371.
Suma'mur. (1996). Higiene Perusahaan dan Keselamatan Kerja. Jakarta: Gunung Agung. Susihono, W., \& Prasetyo, W. (2012). Perbaikan Postur Kerja Untuk Mengurangi Keluhan Muskuloskeletal dengan Pendekatan Metode OWAS. Spektrum Industri, 69-81.

Tarwaka. (2004). Ergonomi untuk Keselamatan, Kesehatan Kerja dan Produktivitas. Surakarta: UNIBA.

Wignjosoebroto, S. (2000). Ergonomi, Studi Gerak dan Waktu. Surabaya: Prisma Printing.

Wignjosoebroto, S. (2008). Ergonomi Studi Gerak dan Waktu. Surabaya: Guna Widya. 